\title{
Application of Statistical Experimental Design to Benzylation of $\boldsymbol{p}$-Chlorophenol
}

\author{
Shams Tania Afroza Islam, Manoranjan Saha*, Dipti Saha, Mohammad Ismail, \\ Mirza Galib and Nashid Sharif \\ Department of Applied Chemistry and Chemical Engineering, University of Dhaka, \\ Dhaka-1000, Bangladesh
}

\begin{abstract}
A $2^{3}$ Yates pattern experimental design was used to develop a mathematical model for the benzylation of $p$-chlorophenol with benzyl alcohol in the presence of perchloric acid as catalyst. A set of trials was planned with two replicates and the centre point trial with 4 replicates according to the design. The critical response was the yield of 2-benzyl-4-chlorophenol. Main effects as well as two- and three- factor interaction effects were statistically significant. The highest experimental yield was $91.6 \%$. The experimental settings were $130^{\circ} \mathrm{C}$, molar ratio of p-chlorophenol to benzyl alcohol 4:1, amount of $60 \%$ perchloric acid $5 \%$ by wt. of p-chlorophenol, addition time $2 \mathrm{~h}$ and stirring time $1 \mathrm{~h}$. The difference between the experimental and predicted yields did not exceed $0.04 \%$.
\end{abstract}

Key words : p-Chlorophenol, Benzyl alcohol, Perchloric acid, 2-benzyl-4-chlorophenol, Experimental design

\section{Introduction}

To protect synthetic fuels, lubricating oils and polymeric materials against thermal degradation due to heat, light, air, oxygen, ozone,etc., use of antioxidants has become increasingly important. Alkylchlorophenols and their derivatives are effective antioxidants and multifunctional stabilizers in such media (Lebedev, 1984; Lee, 1967; Orloff and Napolitano, 1964; Ravikovich, 1964; Starnes, 1972; Shreve and Brink, 1977; Topchiev et al. 1964). Moreover, alkylchlorophenols and their derivatives are also strong herbicides, insecticides and bactericides (Okazaki et al. 1951; Topchiev et al. 1964; Weintraub et al. 1954).

Chlorophenol has been alkylated with cycloalkenes (Kasyanov et al. 1984; Mircea et al. 1970; Saha et al. 1981; Saha and Kasyanov, 1984; Saha, 1986; Saha, 1987; Saha, 1990; Saha et al. 1996), cycloalcohols (Saha and Roy, 1989 ; Saha and Zaman, 1989; Saha et al. 1993; Saha et al. 1998; Topchiev et al. 1964), and cycloalkyhalides (Abdurasulaeva et al. 1973; Langer and Buysch, 1993; Turaeva et al. 1975) in the presence of acidic catalysts by several authors. But no attempt has ever been made to investigate the reaction of pchlorophenol with benzylalcohol. Experimental design is applied for the synthesis of a product in an efficient manner (Clausen 1978; Davies, 1979). Mathematical models have been developed for the alkylatinon of cresols with alkenes and alcohols using statistical design by our research group (Alam et al. 2008; Alam et al. 2008; Saha et al. 2003; Saha et al. 2004; Ismail et al. 2007; Palma et al. 2007).

Aim of the present investigation is to develop a mathematical model for the benzylation of $p$-chlorophenol with benzyl alcohol in the presence of perchloric acid by means of a $2^{3}$ Yates pattern experimental design (Clausen and Matson, 1978).

\section{Materials and Methods}

\section{Matertials}

p-Chlorophenol was collected from the Thomas Baker Chemicals Limited, India. Methylcyclohexanol was obtained from Fluka Chemika, Switzerland and perchloric acid (60\%) from Riedel-deHaen, Germany.

\section{Synthetic procedure}

Reactions were carried out in a three necked round bottom flask fitted with a condenser, a thermometer and a dropping funnel. Stirring was made by a magnetic stirrer and temperature was controlled by the temperature regulator. $p$ Chlorophenol and perchloric acid mixture was heated to the desired temperature and benzyl alcohol was added to it gradually over a certain period of time (addition time, $\mathrm{t}_{\mathrm{a}}$ ) with

\footnotetext{
* Corresponding author: E-mail: : manoranjansaha2005@yahoo.com
} 
constant stirring. The reaction mixture was continued to stir at that temperature for an extended period of time (stirring time, $\mathrm{t}_{\mathrm{s}}$ ) and then cooled to room temperature (Alam et el. 2008).

\section{Isolation of product}

For the isolation of the product, reaction mass was dissolved in toluene and neutralized and washed with distilled water several times. Unconverted reactants and solvent were distilled off at atmospheric pressure. The product was finally distilled to give 2-benzyl-4-chlorophenol (b.p. 295 C) , which was confirmed by spectral and physico-chemical means. The yield was expressed as percentage of theory (Alam et al. 2008 ) .

\section{Analytical and product characterization}

2-Benzyl-4-chlorophenol in 0.01 $\mathrm{M}$ methanol solution absorbed strongly at $\lambda_{\max }=254.00 \mathrm{~nm}$ in the UV-spectrum.

The IR spectrum of the product showed absorption bands at $3540 \mathrm{~cm}^{-1}, 3060 \mathrm{~cm}^{-1}, 2918 \mathrm{~cm}^{-1}, 1600 \mathrm{~cm}^{-1}, 817-890 \mathrm{~cm}^{-1}$ and $653 \mathrm{~cm}^{-1}$ for $-\mathrm{OH}$ group, aromatic $=\mathrm{C}-\mathrm{H}$, saturated

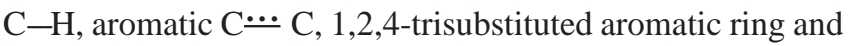
$\mathrm{C}-\mathrm{Cl}$, respectively.

${ }^{13} \mathrm{C}$ NMR $\left(\mathrm{CDCl}_{3}\right): \delta 130.97-115.71,36.33$

The ${ }^{1} \mathrm{H}$ NMR spectrum of the product showed the signals for the following protons (Table I):<smiles></smiles>

Table I. The ${ }^{1} \mathbf{H}$ NMR spectrum of 2-benzyl-4-chlorophenol

\begin{tabular}{l|c|c}
\hline Protons & $\begin{array}{c}\text { Chemical shift } \\
\text { in } \delta \mathrm{ppm}\end{array}$ & $\begin{array}{c}\text { Ratio of integrator } \\
\text { readings }\end{array}$ \\
\hline a,b,c,d & $6.7-7.4$ & 8 \\
$\mathrm{x}$ & 5.1 & 1 \\
$\mathrm{y}$ & $3.9-4.2$ & 2 \\
\hline
\end{tabular}

2- Benzyl-4-chlorophenol had b.p. $295^{\circ} \mathrm{C}, n_{D}{ }^{20} 1.5398$ and $d_{4}^{20} 1.1101$.

\section{Results and Discussion}

$p$-Chlorophenol with benzyl alcohol in the presence of $60 \%$ perchloric acid as catalyst gave 2-benzyl-4-chlorophenol. Three parameters viz. temperature, molar ratio of $p$ chlorophenol to benzyl alcohol and amount of perchloric acid were considered in the development of the mathematical model of the reaction using Yates pattern experimental design (Clausen and Matson, 1978).

The experimental ranges of the variables are listed in Table II. The critical response of interest was the yield of 2-benzyl4-chlorophenol. Addition time of benzyl alcohol to chlorophenol- catalyst mixture was $2 \mathrm{~h}$ and stirring time after the addition of benzyl alcohol was $1 \mathrm{~h}$.

Table II. Process variables and response

\begin{tabular}{l|c|c|c}
\hline Variable & \multicolumn{3}{|c}{ Range } \\
\hline & Low(-) & Mid (0) & High(+) \\
\hline $\mathrm{X}_{1}$, Temperature $\left.{ }^{(0} \mathrm{C}\right)$ & 60 & 95 & 130 \\
$\mathrm{X}_{2}$, Molar ratio of & $3: 1$ & $3.5: 1$ & $4: 1$ \\
$\begin{array}{l}\text {-chlorophenol benzyl alcohol } \\
\mathrm{X}_{3} \text {, Amount of catalyst, } \\
\% \text { by wt. of } p \text {-chlorophenol }\end{array}$ & 1 & 3 & 5 \\
\hline
\end{tabular}

Response : Y-Yield of 2-benzyl-4-chloropehnol

The experimental design used was Yates pattern, 3 factor two level factorial; there were $2^{3}$ i.e. eight trials. Since the basic $2^{3}$ factorial design involves eight trials, each was run in duplicate yielding 16 trials. In order to check the lack of fit due to curvature, additional trial was made at the midpoint level of each factor. The difference between the average centre point value and the overall average of the design points indicated the severity of curvature.

Table III illustrates the two level 3-factor design with the factors in coded form. The experimental runs for trial 1 through 8 were run in duplicate; trial 9 , the centre point trial was run four times, interspersed throughout the experimental run.

The results of these experiments are listed in Table IV. The average yield $\bar{Y}$, the range and the variance were calculated for each trial.

The variance, an estimate of dispersion of data, was calculated by the following formula:

Variance $=\mathrm{S}^{2}=$

$$
\frac{\left(Y_{1}-\bar{Y}\right)^{2}+\left(Y_{2}-\bar{Y}\right)^{2}+\ldots \ldots \ldots \ldots \ldots \ldots \ldots \ldots+\left(Y_{n}-\bar{Y}\right)^{2}}{n-1}
$$


where, $\quad Y=$ response value

$\bar{Y}=$ average or mean of response value

and $\quad n=$ number of observations

For trial 1,

Variance $=\mathrm{S}_{1}{ }^{2}=\frac{(54.6-55.0)^{2}+(55.4-55.0)^{2}}{2-1}=0.32$

and for trial 9,

Variance $=\mathrm{S}_{9}{ }^{2}=$

$\frac{(73.6-743)^{2}+(747-743)^{2}+(739-74.3)^{2}+(75.0-743)^{2}}{4-1}$

$=0.433$

The variances calculated for each trial were then used in the calculation of a weighted average of the individual variances for each trial.

Pooled variance $=\mathrm{S}^{2}$ pooled

$$
=\frac{\left(n_{1}-1\right)\left(S_{1}{ }^{2}\right)+\left(n_{2}-1\right)\left(S_{2}{ }^{2}\right)+\ldots \ldots \ldots \ldots \ldots+\left(n_{K}-1\right)\left(S_{K}{ }^{2}\right)}{\left(n_{1}-1\right)+\left(n_{2}-1\right)+\ldots \ldots \ldots+\left(n_{K}-1\right)}
$$

$=\frac{0.32+0.50+0.72+0.98+0.50+1.28+0.72+1.62+3 \times 0.433}{1+1+1+1+1+1+1+1+3}$

$$
1+1+1+1+1+1+1+1+3
$$$$
=0.7218
$$

The pooled standard deviation is the square root of the pooled variance:

Standard deviation $_{\text {pooled }}=\sqrt{\mathrm{S}^{2} \text { Pooled }}=\sqrt{0.7218}=0.8496$

The pooled standard deviation was used to calculate the minimum observed effect that was statistically significant.

\section{Table III. Experimental design}

\begin{tabular}{l|c|c|c|c}
\hline \multirow{2}{*}{$\begin{array}{l}\text { Trial . } \\
\text { No }\end{array}$} & Replicates & \multicolumn{3}{|c}{ Design } \\
\cline { 3 - 5 } & & $\begin{array}{c}\text { Temperature, } \\
\mathrm{X}_{1}\end{array}$ & $\begin{array}{c}\text { Molar ratio, } \\
\mathrm{X}_{2}\end{array}$ & $\begin{array}{c}\text { Amount of } \\
\text { catalyst, } \mathrm{X}_{3}\end{array}$ \\
\hline 1 & 2 & - & - & - \\
2 & 2 & + & - & - \\
3 & 2 & - & + & - \\
4 & 2 & + & + & - \\
5 & 2 & - & - & + \\
6 & 2 & + & - & + \\
7 & 2 & - & + & + \\
8 & 2 & + & + & + \\
9 & 4 & 0 & 0 & 0 \\
\hline
\end{tabular}

Table IV. Results of three-factor experiment

\begin{tabular}{l|c|c|c|c|c}
\hline \multirow{2}{*}{$\begin{array}{l}\text { Trial } \\
\text { No. }\end{array}$} & \multicolumn{5}{|c}{ Results } \\
\cline { 2 - 4 } & \multicolumn{3}{|c|}{ Yield } & Range & Variance \\
\cline { 2 - 4 } & $\mathrm{Y}_{1}$ & $\mathrm{Y}_{2}$ & $\bar{Y}$ & & \\
\hline 1 & 54.6 & 55.4 & 55.0 & 1 & 0.32 \\
2 & 74.4 & 75.4 & 74.9 & 1 & 0.50 \\
3 & 65.9 & 67.1 & 66.5 & 1 & 0.72 \\
4 & 80.2 & 81.6 & 80.9 & 1 & 0.98 \\
5 & 70.3 & 71.3 & 70.8 & 1 & 0.50 \\
6 & 82.8 & 84.4 & 83.6 & 2 & 1.28 \\
7 & 76.3 & 77.5 & 76.9 & 1 & 0.72 \\
8 & 90.7 & 92.5 & 91.6 & 2 & 1.62 \\
& 73.6 & 74.7 & & & \\
9 & 73.9 & 75.0 & 74.3 & 1 & 0.433 \\
\hline
\end{tabular}

The computation analysis for this experiment is shown in Table V. The design matrix was supplemented with a computation matrix, which was used to detect any interaction effect. This computation matrix was generated by simple algebraic multiplication of the coded factor levels. In trial 1, $\mathrm{X}_{1}$ was minus, $\mathrm{X}_{2}$ was minus, therefore, $\mathrm{X}_{1} \mathrm{X}_{2}$ was plus; in trial 2, $X_{1}$ was plus, $X_{2}$ was minus, therefore $X_{1} X_{2}$ was minus. The column at the far right of the table is the average yield for each trial. The sum +'s row was generated by totaling the response values on each row with a plus for each column. For $\mathrm{X}_{1}$ factor, 74.9+80.9+83.6+91.6=331.0. In the similar manner the sum -'s row was generated. The sum of these two rows should equal the sum of all the average responses and was included as a check on the calculations. The difference row represented the difference between the responses in the four trials when the factor was at a high level and the responses in the four trials when the factor was at a low level. The effect was then calculated by dividing the difference by the number of plus signs in the column.

In the first column, labeled mean, the effect was the mean or average of all data points. The average of the centre point runs, Trial 9, was then subtracted from the mean effect to give a measure of curvature.

The minimum significant factor effect [MIN] and the minimum significant curvature effect [MINC] were again derived from t-test significance criteria.

The relationships are:

$[\mathrm{MIN}]=\mathrm{t} . \mathrm{s} \sqrt{\frac{2}{m \cdot k}}$ and $[\mathrm{MINC}]=\mathrm{t} . \mathrm{s} \sqrt{\frac{1}{m \cdot k}+\frac{1}{c}}$, 
where $\mathrm{t}$ = appropriate value from "t- table" , s = pooled standard deviation, $\mathrm{m}=$ number of plus signs in column, $\mathrm{k}=$ number of replicates in each trial, $\mathrm{c}=$ number of centre points.

The t value of 2.20 is from the student's " $t$ " table for the $95 \%$ confidence level and 11 degrees of freedom (Davies, 1979). The degrees of freedom result from eight trials with two replicates and one trial with four replicates.

Degrees of freedom $=8(2-1)+1(4-1)=11$

The calculations for the minimum significant effects are as follows:

$[\mathrm{MIN}]=2.20 \times 0.8496 \times \sqrt{\frac{2}{4 \times 2}}=0.9346$

$[\mathrm{MINC}]=2.20 \times 0.8496 \times \sqrt{\frac{1}{8 \times 2}+\frac{1}{4}}=1.0449$

TableV. Computation matrix for three factor experiment acid $\left(\mathrm{X}_{1} \mathrm{X}_{2} \mathrm{X}_{3}\right)$ were significant. There was no significant curvature effect.

These results were expressed as a mathematical model using a first order polynomial. The values for the co-efficient were one half the factor effects listed in Table $\mathrm{V}$ since these were based upon coded levels +1 and -1 that differed by two units.

$\mathrm{Y}=75.025+7.725 \mathrm{X}_{1}+3.95 \mathrm{X}_{2}+5.7 \mathrm{X}_{3}-0.45 \mathrm{X}_{1} \mathrm{X}_{2}-$ $0.85 \mathrm{X}_{1} \mathrm{X}_{3}-0.425 \mathrm{X}_{2} \mathrm{X}_{3}+0.925 \mathrm{X}_{1} \mathrm{X}_{2} \mathrm{X}_{3}$

In this equation, the factors were expressed in coded units. These were converted into real units by substituting:

$$
\text { for temperature } \mathrm{T}\left({ }^{0} \mathrm{C}\right), \mathrm{X}_{1}=\frac{T-\frac{130+60}{2}}{\frac{130-60}{2}}=\frac{T-95}{35}
$$

\begin{tabular}{|c|c|c|c|c|c|c|c|c|c|}
\hline \multirow[t]{2}{*}{ Trial } & \multirow[t]{2}{*}{ Mean } & \multicolumn{3}{|c|}{ Design } & \multicolumn{4}{|c|}{ Computation } & \multirow[t]{2}{*}{ Response } \\
\hline & & $\mathrm{X}_{1}$ & $\mathrm{X}_{2}$ & $\mathrm{X}_{3}$ & $\mathrm{X}_{1} \mathrm{X}_{2}$ & $\mathrm{X}_{1} \mathrm{X}_{3}$ & $\mathrm{X}_{2} \mathrm{X}_{3}$ & $\mathrm{X}_{1} \mathrm{X}_{2} \mathrm{X}_{3}$ & \\
\hline 1 & + & - & - & - & + & + & + & - & 55.0 \\
\hline 2 & + & + & - & - & - & - & + & + & 74.9 \\
\hline 3 & + & - & + & - & - & + & - & + & 66.5 \\
\hline 4 & + & + & + & - & + & - & - & - & 80.9 \\
\hline 5 & + & - & - & + & + & - & - & + & 70.8 \\
\hline 6 & + & + & - & + & - & + & - & - & 83.6 \\
\hline 7 & + & - & + & + & - & - & + & - & 76.9 \\
\hline 8 & + & + & + & + & + & + & + & + & 91.6 \\
\hline Sum +'s & 600.2 & 331.0 & 315.9 & 322.9 & 298.3 & 296.7 & 298.4 & 303.8 & \\
\hline Sum -'s & 0.0 & 269.2 & 284.3 & 277.3 & 301.9 & 303.5 & 301.8 & 296.4 & \\
\hline Sum & 600.2 & 600.2 & 600.2 & 600.2 & 600.2 & 600.2 & 600.2 & 600.2 & \\
\hline Diff. & 600.2 & 61.8 & 31.6 & 45.6 & -3.6 & -6.8 & -3.4 & 7.4 & \\
\hline Effect & 75.025 & $15.45 *$ & $7.9 *$ & $11.4 *$ & $-0.9 *$ & $-1.7^{*}$ & $-0.85 *$ & $1.85 *$ & \\
\hline
\end{tabular}

Curvature $=75.025-74.3=0.725$

Applying these criteria to the calculated effects, it was seen that the effects of temperature $\left(\mathrm{X}_{1}\right)$, molar ratio of $p$ chlorophenol to benzyl alcohol $\left(\mathrm{X}_{2}\right)$, amount of perchloric acid $\left(\mathrm{X}_{3}\right)$ and interactions between temperature and amount of perchloric acid $\left(\mathrm{X}_{1} \mathrm{X}_{3}\right)$, temperature and molar ratio of $p$ chlorophenol to benzyl alcohol $\left(\mathrm{X}_{1} \mathrm{X}_{2}\right)$, molar ratio of $p$ chlorophenol to benzyl alcohol and amount of catalyst $\left(\mathrm{X}_{2} \mathrm{X}_{3}\right)$ and interaction among temperature, molar ratio of $p$ chlorophenol to benzyl alcohol and amount of perchloric for the amount of catalyst $(y), x_{3}=\frac{y-\frac{5+1}{2}}{\frac{5-1}{2}}=\frac{y-3}{2}$

These substitutions yielded the following final expression:

$\mathrm{Y}=75.025+7.725\left(\frac{T-95}{35}\right)+3.95\left(\frac{m-3.5}{0.5}\right)$ 
$+5.70\left(\frac{y-3}{2}\right) ? 0.45\left(\frac{T-95}{35}\right)\left(\frac{m-3.5}{0.5}\right)$

$-0.85\left(\frac{T-95}{35}\right)\left(\frac{y-3}{2}\right) ? 0.425\left(\frac{m-3.5}{0.5}\right)\left(\frac{y-3}{2}\right)$

$+0.925\left(\frac{T-95}{35}\right)\left(\frac{m-3.5}{0.5}\right)\left(\frac{y-3}{2}\right)$

$=-24.9786+0.6246 \mathrm{~T}+19.15 \mathrm{~m}+14.2786 \mathrm{y}-0.105 \mathrm{Tm}-$ $0.1046 \mathrm{Ty}-2.9357 \mathrm{my}+0.0264 \mathrm{Tmy}$

For trial 1 , temperature $(\mathrm{T})=60^{\circ} \mathrm{C}$, molar ratio of $p$ chlorophenol to benzyl alcohol $(\mathrm{m}: 1)=3: 1$ and the amount of catalyst $(y)=1 \%$ by wt. of $p$-chlorophenol. Therefore, yield calculated from the derived model,

$Y_{(\text {cal. })}=-24.9786+0.6246 \times 60+19.15 \times 3+14.2786 \times 1-0.105$ $\times 60 \times 3-0.1046 \times 60 \times 1-2.9357 \times 3 \times 1+0.0264 \times 60 \times 3 \times 1$

Experimental average yield of the trial 1, $\mathrm{Y}_{\text {(exp.) }}=54.9949$

Hence, deviation $=0.0051$ and percentage deviation $=$ 0.0093

All the values of the experimental average yield and the calculated yield from the derived equation are shown in Table VI .

The discrepancies between the experimental and calculated values did not exceed $0.0402 \%$.

Table VI - Experimental average yield and calculated yield

\begin{tabular}{l|c|c|c|c}
\hline Trial & $\mathrm{Y}_{\text {(exp.) }}$ & $\mathrm{Y}_{\text {(cal.) }}$ & Deviation & $\begin{array}{c}\text { Percentage } \\
\text { deviation }\end{array}$ \\
\hline 1 & 55.0 & 54.9949 & 0.0051 & 0.0093 \\
2 & 74.9 & 74.8888 & 0.0112 & 0.0150 \\
3 & 66.5 & 66.4931 & 0.0069 & 0.0104 \\
4 & 80.9 & 80.8851 & 0.0149 & 0.0184 \\
5 & 70.8 & 70.7844 & 0.0149 & 0.0210 \\
6 & 83.6 & 83.5664 & 0.0336 & 0.0402 \\
7 & 76.9 & 76.8759 & 0.0241 & 0.0313 \\
8 & 91.6 & 91.5479 & 0.0241 & 0.0263 \\
\hline
\end{tabular}

\section{Conclusion}

By means of a Yates pattern experimental design, a polynomial model was developed to predict the yield of 2-benzyl4-chlorophenol in the reaction of p-chlorophenol with benzyl alcohol in the presence of $60 \%$ perchloric acid as cata- lyst. Adequacy of the suggested model was checked up. The discrepancy between the experimental and predicted yields was negligible.

\section{References}

Abdurasulaeva A. R., Akhmedov K. N. and Turaeva M. K., (1973) Cycloalkylation of 4-chlorophenol and 4chloroanisole. Zh. Organ. Khim. 9(1): 132-135.

Alam M. Z., Alam A., Kamruzzaman M., Kunitha S. and Saha M. (2008) Development of a mathematical model by means of experimental design for allkylation of mcresol with cyclopentene. Chem. Eng. J. (Elsevier). 137: 598-602.

Alam A., Alam M. Z., Alam Islam, S. T. A. Alam and S., Saha M. (2008) Application of Statistical design to benzylation of toluene with benzyl alcohol. Chem. Eng. Technol. 31(3): 417-420.

Clausen C. A. (1978) Matson, G. Principles of Industrial Chemistry. (Willey Interscience Publication, New York) pp 412.

Davies O. L. (1979) Design and Analysis of Industrial Experiments. 2nd Ed. (Longman London) pp 636.

Ismail M., Jamal M. S., Islam S. T. A., Ashaduzzaman M. and Saha M. (2007) A mathematical model for the benzylation of $p$-cresol with benzyl alcohol. Bangladesh $J$. Sci Ind. Res. 42(2): 187-194.

Kasyanov V. V., Muganlinskii F. F. and Saha M. (1984) Study of alkylation of o-chlorophenols by cyclohexene. Azerb. Khim. Zh. 5: 14-18.

Kasyanov V. V., Muganlinskii F. F. and Saha M. (1984) Kinetics and mechanism of the alkylation of chlorophenols with cyclohexene. Kinetics and Catalysis, Acad. Sci. USSR, Moscow. Translated Journal (English), Plenum Publishing Corporation, New York. 25(1): 13-17.

Langer R. and Buysch H. J. (1993) Process for monobenzylation of p-substituted phenols. Eur. Pat. Appl. Exp. 538.704 (Cl. C07C37/16)- Chem. Abstr. 1995, 122,31111d.

Lebedev N. N. (1984) Chemistry and Technology of Basic Organic and Petrochemical Synthesis. 1st Ed. (Mir Publishers, Moscow) pp 638. 
Lee D. H. (1967) Mineral lubricating oil containing bisphenol, detergent and phosphate additives. US Patent. 3296134.

Mircea I., Maria M. and Nicolae M. (1970) Cyclohexyl chlorophenol. Bull. Soc. Chim. Fr. 11: 4004 - 4005.

Okazaki K., Kato H. and Matusi K. (1951). Relation between bactericidal and insecticidal activities $J$. Pharm. Soc. Japan. 71: 495.

Orloff H. D. and Napolitano J. P. (1964) Stabilises organic materials. US Patent. 3146273.

Palma B. S., Azim M. A., Ismail M., Saha D., Kader M. A. and Saha M. (2007) A mathematical model for the indylation of m-cresol with indene in the presence of benzene sulphonic acid. Bangladesh J. Sci. Ind. Res. 42(1): 1-8.

Ravikovich A. M. (1964) Antioxidants for mineral and synthetic oils. Chemistry and technology for fuels and oils. 11: 64-71.

Saha M. (1986) Studies on the reaction of 2,4-dichlorophenol with cyclohexene. Bangladesh J. Sci. Res. 4(1): 8392.

Saha M. (1987) Reaction of chlorophenol with cyclohexene in the presence Bangladesh J. Sci. Res. 5(1): 113-119.

Saha M. (1990) Reaction of p- chlorophenol with cyclopentene. J. Bangladesh Acad. Sci. 14(2): 241-245.

Saha M., Bhuiyan M. S. I., Rafique R. F. and Hasan M. M. (2003) A mathematical model for the rection of $\mathrm{m}$ cresol with indene in the presence of sulphuric acid. Dhaka Univ. J. Sci. 51(1): 7-12. Chem. Abstr. 140 (2004) $198857 \mathrm{~K}$.

Saha, M. Biswas, S. Nahar, N. (1993) Cycloalkylation of pchlorophenol. Bangladesh J. Sci. Ind. Res. 28 (2): 150153.

Saha M., Biswas S., Basak P. K. and Saha D. (1998) Alkylation of $p$-chlorophenol with $n$-alcohols. Bangladesh J. Sci. Ind. Res. 33(4): 518-520.
Saha M., Biswas S., Saha S. K. and Rafique R. F. (2004) A mathematical model for the alkylation of p-cresol with tert.- amyl alcohol in the presence of sulphuric acid. Bangladesh J. Sci. Ind. Res. 39 (3-4): 139-146.

Saha M., Ghosh S. K., Zaman M. B., Mahmud H. N. M. E., Sarker M. A. B., Jolly Y. N. and Chuodhury S. (1996) Cycloalkylation of $p$-chlorophenol with cycloalkenes in the presence of of borontrifluoride etherate. Bangladesh J. Sci. Ind. Res. 31(3): 1-8.

Saha M. and Kasyanov V. V. (1981) Reaction of pchlorophenol by cycloolefins in the presece of sulphuric acid. Sintezi Prevrashen. Geteroatomsoderzh. Organ. Soedin. Baku. 26-34.

Saha M. and Roy R. K. (1989) Reaction of p-chlorophenol with cyclohexanol. Bangladesh J. Sci. Ind. Res. 24(14): 41-45.

Saha M. and Zaman M. B. (1989) Cyclohexylation of $p$ chlophenol. Dhaka Univ. Studies. 37(2): 153-158.

Shreve R. N. and Brink J. A. (1977) Chemical Process Industries, 4th Ed., (McGraw-Hill International Book Company, London) pp 814.

Starnes W. H. (1972) Unusual antioxidant behaviour of hindered chlorophenols in metal containing systems. Tetrahedron Letters. 25: 34743-34746.

Topchiev A. V., Zavgorodii S. V. and Kruchkova V. G. (1964) Alkylation with olefins. (Elsevier Publishing Company, Amstardam-London-NewYork), pp 306.

Turaeva M. K., Akhmedov K. N., Abdurasuleva A. R. (1975) Alkylation of 2- and 4-chlorophenols, 4-chloroanisole by alkylhalides in the presence of salts of iron and zinc. Ruc. Dep. VINITI. Tashkent. 3172-3175.

Weintraub R. L., Brown J. W. and Trone J. A. (1954) Herbicidal activity. J. Agr. \& Food Chem. 2(19): 996999.

Received : October 12, 2008;

Accepted : September 15, 2009 